\title{
Surgery for advanced-stage non-small cell lung cancer: lobectomy or sub-lobar resection?
}

\author{
Zhexue Hao ${ }^{1 \#}$, Hengrui Liang ${ }^{1 \#}$, Yichi Zhang ${ }^{2 *}$, Wei Wei ${ }^{3}$, Yuting Lan ${ }^{2}$, Shuxian Qiu ${ }^{2}$, Guo Lin ${ }^{2}$, \\ Runchen Wang ${ }^{2}$, Yulin Liu ${ }^{2}$, Yingying Chen ${ }^{2}$, Jun Huang ${ }^{1}$, Wei Wang ${ }^{1}$, Fei Cui ${ }^{1}$, Taichiro Goto ${ }^{4}$, \\ Jin Yong Jeong ${ }^{5}$, Giulia Veronesi ${ }^{6,7}$, Alberto Lopez-Pastorini ${ }^{8}$, Hitoshi Igai ${ }^{9}$, Wenhua Liang ${ }^{1}$, Jianxing He $^{1}$, \\ Jun Liu ${ }^{1}$
}

${ }^{1}$ Department of Thoracic Surgery and Oncology, The First Affiliated Hospital of Guangzhou Medical University, State Key Laboratory of Respiratory Disease, National Clinical Research Center for Respiratory Disease, Guangzhou Institute of Respiratory Health, Guangzhou, China; ${ }^{2}$ Department of Clinical Medicine, Guangzhou Medical University, Guangzhou, China; ${ }^{3}$ Department of Thoracic Surgery, Huizhou Municipal Central Hospital, Huizhou, China; ${ }^{4}$ Lung Cancer and Respiratory Disease Center, Yamanashi Central Hospital, Yamanashi, Japan; ${ }^{5}$ Department of Thoracic and Cardiovascular Surgery, Incheon St. Mary's Hospital, College of Medicine, The Catholic University of Korea, Seoul, Republic of Korea; ${ }^{6}$ Division of Thoracic Surgery, IRCCS San Raffaele Scientific Institute, Milan, Italy; ${ }^{7}$ School of Medicine, Vita-Salute San Raffaele University, Milan, Italy; ${ }^{8}$ Department of Thoracic Surgery, Lung Clinic, Hospital of the City of Cologne, University of Witten-Herdecke, Cologne, Germany; ${ }^{9}$ Department of General Thoracic Surgery, Japanese Red Cross Maebashi Hospital, Maebashi, Gunma, Japan

Contributions: (I) Conception and design: Z Hao, H Liang, Y Zhang, W Liang, J He; (II) Administrative support: J He, W Liang, J Liu; (III) Provision of study materials or patients: Z Hao, H Liang, Y Zhang, W Wei, W Wang, F Cui; (IV) Collection and assembly of data: Z Hao, W Wang, J He, F Cui, Y Liu, G Lin; (V) Data analysis and interpretation: H Liang, J Liu, J He; (VI) Manuscript writing: All authors; (VII) Final approval of manuscript: All authors.

\#These authors contributed equally to this work.

Correspondence to: Jun Liu; Jianxing He, MD; Wenhua Liang, MD. Department of Thoracic Surgery and Oncology, The First Affiliated Hospital of Guangzhou Medical University, Yanjiang Road 151\#, Yuexiu District, Guangzhou 510120, China; State Key Laboratory of Respiratory Disease, Guangzhou 510120, China; National Clinical Research Center for Respiratory Disease, Guangzhou 510120, China; Guangzhou Institute of Respiratory Health, Guangzhou 510120, China. Email: liangwh1987@163.com; drjianxing.he@gmail.com; liujun9707@sina.com.

Background: Metastatic non-small cell lung cancer (NSCLC) has many comorbidities, such as chronic obstructive pulmonary disease, coronary heart disease, and older age-related comorbidities. A survival benefit was observed in such patients who underwent surgery for selected oligometastatic disease. However, to the best of our knowledge, there is no evidence to support whether lobectomy (compared with sub-lobar resection) would further prolong these patients' lives.

Methods: Patients with metastatic NSCLC who underwent primary tumor resection were identified from the Surveillance, Epidemiology, and End Results (SEER) database and then divided into lobectomy and sub-lobar resection groups. Propensity score matching (PSM, 1:1) was performed to match the baseline characteristics of the two groups. Cancer-specific survival (CSS) was estimated.

Results: In total, 24,268 patients with metastatic NSCLC were identified; 4,114 (16.95\%) underwent primary tumor surgery, and of these, 2,045 (49.71\%) underwent lobectomy and 1,766 (42.93\%) underwent sub-lobar resection. After PSM, 644 patients in each group were included. Lobectomy was independently correlated with longer median CSS time [hazards ratio (HR): 0.70, 95\% confidence interval (CI): 0.61-0.80, $\mathrm{P}<0.001]$. The 1, 2, and 3-year survival rates after PSM also favored the lobectomy group. However, no significant survival difference was found for wedge resection and segmentectomy (HR: 0.96, 95\% CI: 0.70-1.31, P=0.490). The 1-, 2-, and 3-year survival rates after PSM also exhibited no difference within the sub-lobar group. We explored whether lymph node dissection would provide additional survival benefits for stage IV NSCLC patients. According to the multivariate Cox analysis of the matched population, lymph node dissection was independently associated with better CSS (HR: 0.76, 95\% CI: 0.66-0.88, P<0.001) and overall survival (OS) (HR: 0.74, 95\% CI: 0.65-0.86, $\mathrm{P}<0.001$ ). We confirmed this result in the different types 
of surgery and found that the lymph node dissection group consistently had better survival outcomes both in the lobectomy group and sub-lobar resection population. According to the subgroup analysis, with the exception of stage T4 and brain metastatic patients, all of the patient subtypes exhibited greater benefit from lobectomy than sub-lobar resection.

Conclusions: Lobectomy has a greater survival benefit in metastatic NSCLC patients compared with sublobar resection when radical treatment of primary site was indicated.

Keywords: Metastatic non-small cell lung cancer (metastatic NSCLC); surgery; Surveillance, Epidemiology, and End Results database (SEER database); lobectomy; sub-lobar resection

Submitted Sep 24, 2020. Accepted for publication Mar 23, 2021.

doi: $10.21037 /$ tlcr-21-39

View this article at: http://dx.doi.org/10.21037/tlcr-21-39

\section{Introduction}

Lung cancer is one of the leading causes of cancer death worldwide (1). Approximately $85 \%$ of patients with lung cancer have non-small cell lung cancer (NSCLC) (2). The 5 -year survival rate of these patients has been reported to be $12-15 \%$, and approximately $60 \%$ are diagnosed with stage IV disease on first diagnosis (3). Patients with NSCLC usually have comorbidities as well, such as chronic obstructive pulmonary disease, coronary heart disease, and/ or age-related comorbidities (4). Compared with early-stage NSCLC, indication to surgery for advanced-stage NSCLC requires accurate selection of candidates.

The recommended treatment for stage IV NSCLC is usually systemic therapy (i.e., chemotherapy, molecular targeted therapy, or immune therapy) (5). Traditionally, the stage IV treatment strategy for NSCLC does not include curative-intent local therapy (surgery or radiation), and the therapeutic goals are focused on disease control, palliation, and optimization of the quality of life. However, several recent clinical studies have shown that local consolidative therapy may be beneficial for certain stage IV NSCLC patients can and improve overall survival (OS) $(6,7)$. Gomez et al. conducted a phase II clinical trial that considered the effects of local consolidative therapy in oligometastatic disease (8). The updated long-term outcomes indicated that patients receiving local consolidative therapy had better progression-free survival (PFS) (14.2 vs. 4.4 months, $\mathrm{P}=0.022)$ and $\mathrm{OS}$ (41.2 vs. 17 months; $\mathrm{P}=0.017)$.

Lobectomy and systematic lymph node dissection are the gold standard treatment modalities for early-stage NSCLC. Recently published studies have indicated that primary tumor resection (would also be) is beneficial for stage IV NSCLC patients after systemic treatment in presence of a single or few synchronous metastatic sites and improves their OS (9-11). However, to the best of our knowledge, no study has explored which surgery type (lobectomy or sub-lobar resection) provides the greater survival benefit in these patients.

To address this unresolved issue, we performed a population-based study to determine whether lobectomy or sub-lobar resection would have the greater benefit in stage IV NSCLC patients. We present the following article in accordance with the STROBE reporting checklist (available at http://dx.doi.org/10.21037/tlcr-21-39).

\section{Methods}

\section{The Surveillance, Epidemiology, and End Results (SEER) database}

The SEER database is a national population-based reporting system that collects tumor-related data, covering approximately $28 \%$ of the US population (12). The SEER data are publicly available for studies of cancer-based epidemiology and survival analyses. We received permission to access the data used in the present study (SEER-Stat username: 11136-Nov2018). The study was conducted in accordance with the Declaration of Helsinki (as revised in 2013).

Cases of lung cancer (C34.0-34.9) diagnosed from 2004 to 2016 were extracted from the SEER database (SEERStat 8.3.6) according to the site code classifications. This range was selected because the American Joint Committee on Cancer (AJCC) TMN stage and collaborative stage information became available in 2004. We reclassified the TNM stage according to the AJCC 8th edition. Patients who underwent stage IV primary tumor resection, 
histologically confirmed as NSCLC, were enrolled. Patients were excluded if the record of the surgery (to) performed on the primary site was (unknown) unavailable. Other exclusion criteria were as follows: $<18$ years old, unknown TNM stage, unknown time of survival, unknown treatment modality, not the first tumor, and $>1$ tumor.

\section{Statistical analysis}

The study sample was divided according to the surgical resection strategy for the primary tumor: lobectomy versus sub-lobar resection. The propensity score matching (PSM) generated from (the) logistic regression was performed to minimize differences in the confounding variables and facilitate matching patients in the 2 treatment groups (R software version 2.15.1, https://cran.r-project.org/). Variables that could influence the outcomes of treatment were used to generate a propensity score, including age, sex, histology, TNM stage, differentiation grade, and tumor site. Patients were 1:1 matched on the basis of PSM using the nearest-neighbor method on the logit scale. The caliper was set at 0.01 . After PSM, the standardized mean differences (SMD) before and after PSM were calculated. Confounding variables were considered comparable when SMD were $<0.10$.

OS, cancer-specific survival (CSS), and survival months were extracted from the SEER database. OS was defined as the time from diagnosis to death from any cause; living patients were excluded at the time of the last recording. CSS was defined as the date of diagnosis to the date of cancerspecific death. OS and CSS were estimated by the KaplanMeier (K-M) method and compared with the log-rank test. Univariate and multivariate Cox proportional hazard regression analyses were used to determine independent prognostic factors. Hazard ratios (HRs) were calculated with a $95 \%$ confidence interval (CI).

The normality of the data was assessed by the ShapiroWilk test. Continuous variables were given as means and standard deviations. Student's $t$-test or Mann-Whitney $\mathrm{U}$-test was performed to compare differences between groups with continuous variables. Distribution of categorical variables was presented as counts and percentages. The $\chi^{2}$-test or Fisher's exact test for small samples was used to compare categorical variables. Subgroup analysis was conducted according to the different clinical population types. Statistical analysis was performed with SPSS version 24.0 (IBM, Armonk, NY, USA); statistical tests were twosided, and $\mathrm{P}<0.05$ was considered statistically significant.

\section{Results}

\section{Demographic characteristics before and after PSM}

In total, 476,757 NSCLC patients were identified for the period from 2004 to 2016 in the SEER database, of which 24,268 stage IV NSCLC patients met the inclusion criteria. The screening process is shown in Figure 1. Of all the eligible patients, 4,114 (16.95\%) underwent surgical treatment of the primary tumor site; 2,045 (49.71\%) of these underwent lobectomy and 1,766 (42.93\%) underwent sub-lobar resection. The remaining patients underwent pneumonectomy and biopsy, which were not included in this analysis. Obvious differences in age, histology, differentiation, tumor site, TNM stage, radiation chemotherapy, and distal surgery were noted between the lobectomy and sub-lobar resection groups (Table 1). This indicated that the baseline characteristics of the two groups did not match. Specifically, the lobectomy group had lower T-stage patients. After the 1:1 PSM, 1,288 stage IV NSCLC patients treated with lobectomy $(\mathrm{n}=644)$ or sub-lobar resection $(n=644)$ were enrolled in the survival analysis. The baseline characteristics of the two groups were all well matched (Table 1).

Logistic analysis was performed to (evaluated) determine which variables were associated with lobectomy (Table 2). Compared with patients $<60$ years, patients $>75$ years were more likely to undergo sub-lobar resection than lobectomy (HR: 0.71, 95\% CI: 0.55-0.91, P=0.007). In addition, T4 patients underwent fewer lobectomies than $\mathrm{T} 1$ or $\mathrm{T} 2$ patients. Patients who received radiation therapy also underwent more lobectomies than patients who did not receive radiotherapy (HR: 1.30, 95\% CI: $1.08-1.56$, $\mathrm{P}=0.005)$.

\section{Impact of surgery types on survival outcomes in stage IV NSCLC patients}

$\mathrm{K}-\mathrm{M}$ analysis and the log-rank test were used in the matched population; patients who underwent lobectomy had longer CSS and OS compared with patients who underwent sub-lobar resection. The median CSS time was 29 months for patients who underwent lobectomy and 18 months for patients who underwent sub-lobar resection after PSM (HR: $0.70,95 \%$ CI: $0.61-0.80, \mathrm{P}<0.001$ ) (Figure 2A). The median OS was 25 and 16 months in the lobectomy and sub-lobar resection groups, respectively (HR: $0.73,95 \%$ CI: $0.65-0.83, \mathrm{P}<0.001$ ) (Figure $2 B$ ). The 


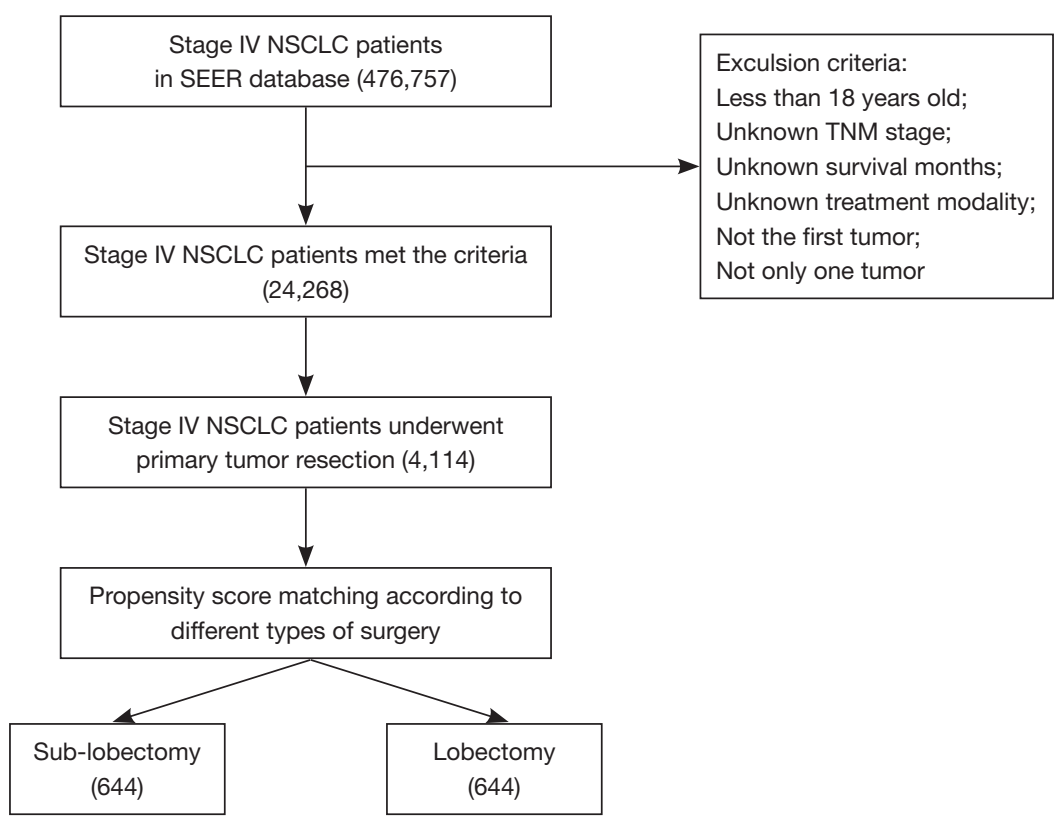

Figure 1 Flowchart of patient screening. NSCLC, non-small cell lung cancer; SEER, the Surveillance, Epidemiology, and End Results.

Table 1 Demographic information (for) on patients with stage IV non-small cell lung cancer before and after PSM

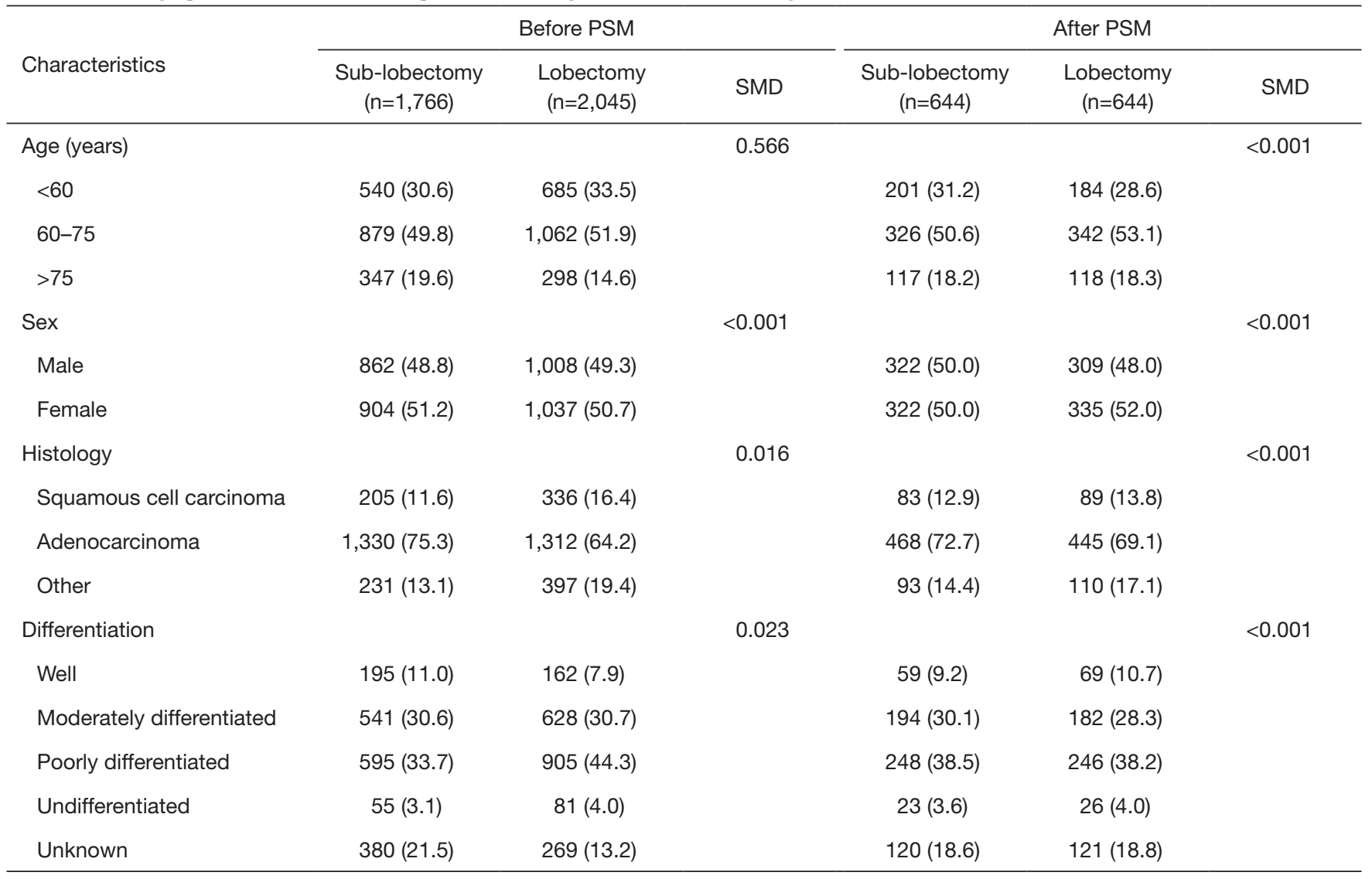

Table 1 (continued) 
Table 1 (continued)

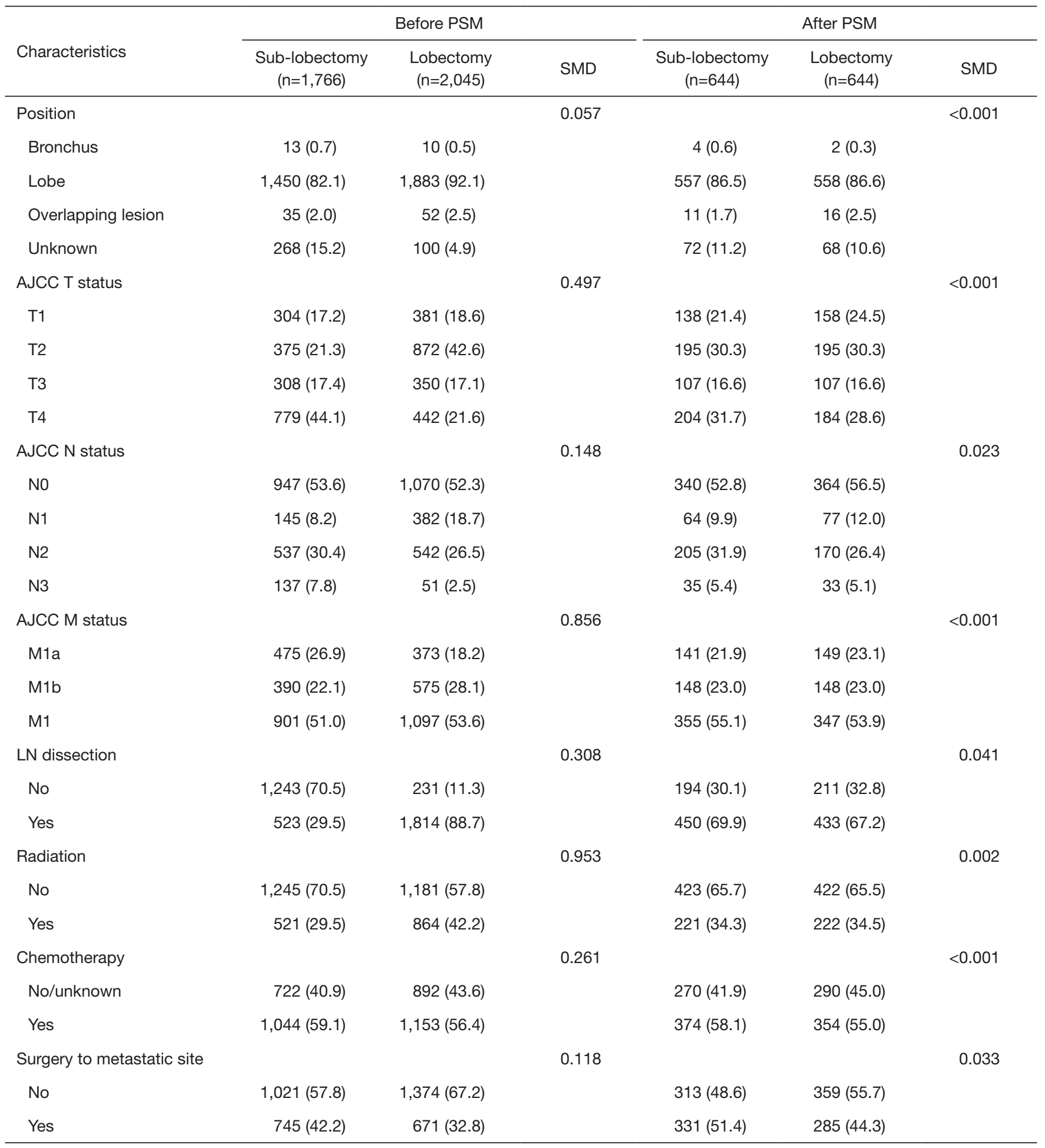

AJCC, American Joint Committee on Cancer; LN, lymph node; NSCLC, non-small cell lung cancer; PSM, propensity score matching; SMD, standardized mean differences. 
Table 2 Logistic regression model (for) of stage IV non-small cell lung cancer patients who underwent lobectomy or sub-lobar resection

\begin{tabular}{|c|c|c|c|c|}
\hline Characteristics & \multicolumn{2}{|c|}{ Univariate analysis } & \multicolumn{2}{|c|}{ Multivariate analysis } \\
\hline \multicolumn{5}{|l|}{ Age (years) } \\
\hline$<60$ & 1.00 (reference) & - & 1.00 (reference) & - \\
\hline $60-75$ & $0.94(0.78-1.34)$ & 0.531 & $0.94(0.78-1.14)$ & 0.551 \\
\hline \multicolumn{5}{|l|}{ Sex } \\
\hline Male & 1.00 (reference) & - & - & - \\
\hline Female & $1.02(0.86-1.20)$ & 0.859 & - & - \\
\hline \multicolumn{5}{|l|}{ Histology } \\
\hline Other & $1.06(0.77-1.45)$ & 0.732 & $1.05(0.78-1.43)$ & 0.742 \\
\hline \multicolumn{5}{|l|}{ Differentiation } \\
\hline Well & 1.00 (reference) & - & - & - \\
\hline Moderately differentiated & $0.96(0.71-1.31)$ & 0.805 & - & - \\
\hline Poorly differentiated & $0.98(0.72-1.33)$ & 0.884 & - & - \\
\hline Undifferentiated & $0.84(0.49-1.45)$ & 0.535 & - & - \\
\hline Unknown & $1.06(0.75-1.50)$ & 0.731 & - & - \\
\hline \multicolumn{5}{|l|}{ Position } \\
\hline T1 & 1.00 (reference) & - & 1.00 (reference) & - \\
\hline $\mathrm{T} 2$ & $1.62(1.28-2.06)$ & $<0.001$ & $1.61(1.27-2.04)$ & $<0.001$ \\
\hline T3 & $1.18(0.89-1.56)$ & 0.244 & $1.17(0.89-1.55)$ & 0.257 \\
\hline $\mathrm{T} 4$ & $0.76(0.60-0.97)$ & 0.029 & $0.76(0.60-0.97)$ & 0.025 \\
\hline \multicolumn{5}{|l|}{ AJCC $\mathrm{N}$ status } \\
\hline NO & 1.00 (reference) & - & 1.00 (reference) & - \\
\hline $\mathrm{N} 1$ & 1.46 (1.23-1.90) & 0.004 & $1.45(1.12-1.88)$ & 0.005 \\
\hline $\mathrm{N} 2$ & $0.81(0.66-0.98)$ & 0.029 & $0.80(0.66-0.97)$ & 0.020 \\
\hline N3 & $0.55(0.37-0.84)$ & 0.005 & $0.55(0.36-0.83)$ & 0.005 \\
\hline
\end{tabular}

Table 2 (continued) 
Table 2 (continued)

\begin{tabular}{|c|c|c|c|c|}
\hline Characteristics & \multicolumn{2}{|c|}{ Univariate analysis } & \multicolumn{2}{|c|}{ Multivariate analysis } \\
\hline \multicolumn{5}{|l|}{ AJCC M status } \\
\hline M1a & 1.00 (reference) & - & 1.00 (reference) & - \\
\hline M1b & $1.25(0.97-1.61)$ & 0.088 & $1.24(0.96-1.60)$ & 0.002 \\
\hline \multicolumn{5}{|c|}{ Lymph node dissection } \\
\hline No & 1.00 (reference) & - & 1.00 (reference) & - \\
\hline Yes & $15.47(12.91-18.54)$ & $<0.001$ & $15.32(12.82-18.30)$ & $<0.001$ \\
\hline \multicolumn{5}{|l|}{ Radiation } \\
\hline \multicolumn{5}{|l|}{ Chemotherapy } \\
\hline No & 1.00 (reference) & - & - & - \\
\hline Yes & $0.95(0.79-1.13)$ & 0.537 & - & - \\
\hline
\end{tabular}

AJCC, American Joint Committee on Cancer; $\mathrm{Cl}$, confidence interval.

1-, 2-, and 3-year survival rates after PSM also favored the lobectomy group (Table 3).

\section{Primary tumor lobectomy as an independent prognostic factor for survival in stage IV NSCLC patients}

In the multivariate Cox analysis of the matched population, lobectomy was found to be independently associated with better CSS (HR: 0.67, 95\% CI: 0.58-0.77, P<0.001) and OS (HR: 0.69, 95\% CI: 0.61-0.79, $\mathrm{P}<0.001$ ) (Table 4). Age, sex, TNM stage, histology, differentiation, lymph node dissections, chemotherapy, and radiotherapy were all independent factors for survival of stage IV NSCLC patients.

\section{Impact of sub-lobar resection on survival outcomes in stage IV NSCLC patients}

We divided the sub-lobar resection population into wedge resection and segmentectomy groups. PSM analysis was conducted to match demographic information, which is shown in the supplementary materials. K-M analysis and the log-rank test were used in the matched population. Patients who underwent wedge resection had similar CSS and OS compared with segmentectomy. The median CSS time was 16 months for patients who underwent wedge resection and 17 months for patients who received segmentectomy after PSM (HR: 0.96, 95\% CI: 0.70-1.31, $\mathrm{P}=0.490$ ) (Figure 2C). The median OS was 14 and 16 months in the wedge resection and segmentectomy groups, respectively (HR: 0.96, 95\% CI: $0.71-1.30, \mathrm{P}=0.490$ ) (Figure $2 D$ ). The 1 -, 2-, and 3-year survival rate after PSM also exhibited no difference in the sub-lobar group (Table 5).

\section{Impact of lymph node dissection on survival outcomes in stage IV NSCLC patients}

In the present study, we investigated whether lymph node dissection would provide additional survival benefit in stage IV NSCLC patients. According to the multivariate Cox analysis of the matched population, lymph node dissection was independently associated with better CSS (HR: 0.76, 95\% CI: $0.66-0.88, \mathrm{P}<0.001)$ and OS (HR: 0.74, 95\% CI: $0.65-0.86, \mathrm{P}<0.001$ ) (Table 4). We confirmed this result for different types of surgery and found that the lymph node dissection group consistently had better survival outcomes in both the lobectomy group and sub-lobar resection population (Figure $3 A, B, C, D$ ). We further divided all of the 
A

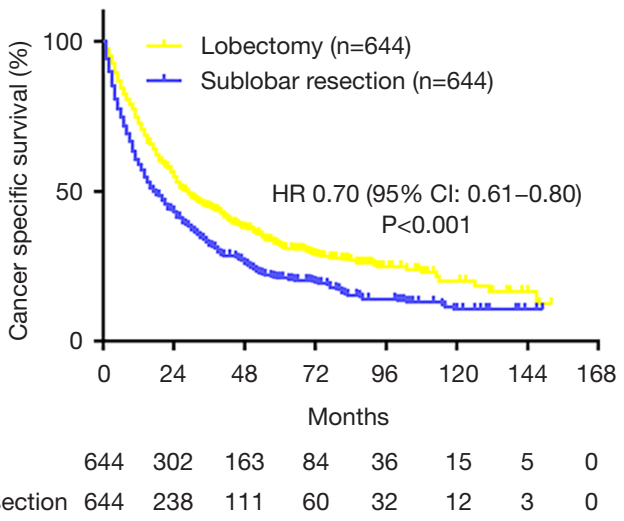

C

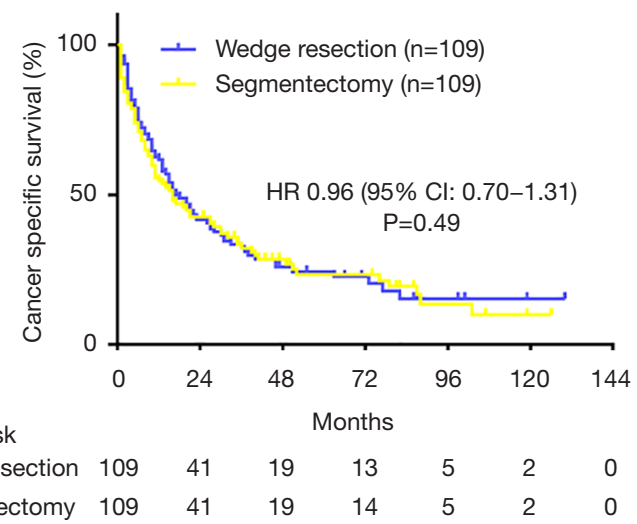

B

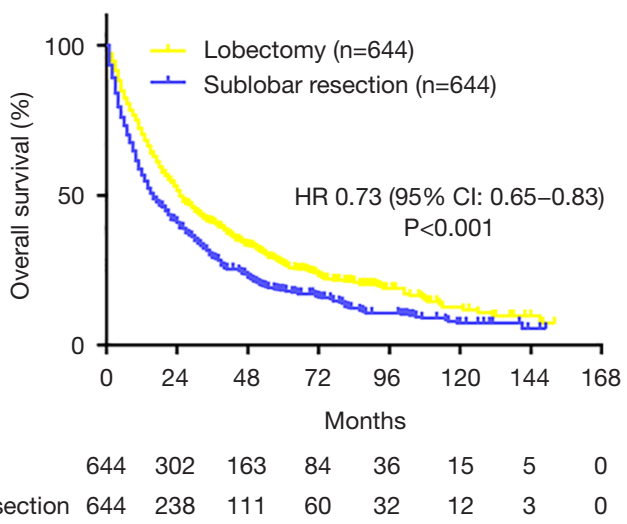

D

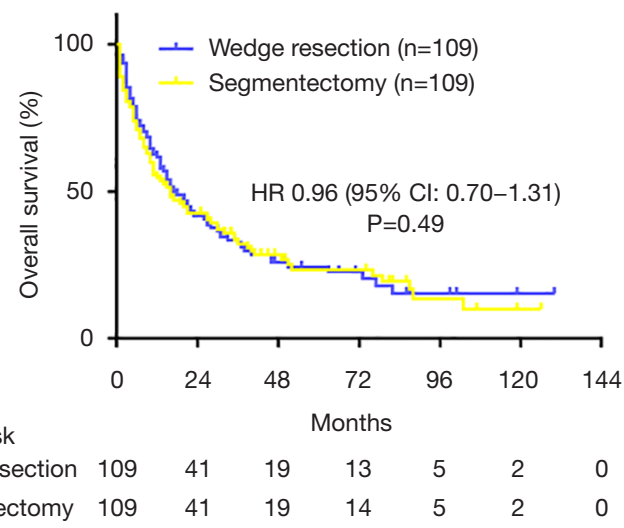

Figure 2 Kaplan-Meier plot of survival outcomes for stage IV non-small cell lung cancer patients according to surgery type. (A) Cancerspecific survival of lobectomy $v s$. sub-lobar resection; (B) overall survival of lobectomy $v s$. sub-lobar resection; (C) cancer-specific survival of wedge resection $v s$. segmentectomy; (D) overall survival of wedge resection vs. segmentectomy. HR, hazard ratio; CI, confidence interval.

Table 3 Survival rate of stage IV non-small cell lung cancer patients according to (different types of) surgery type

\begin{tabular}{lcccc}
\hline \multirow{2}{*}{ Survival rate } & \multicolumn{2}{c}{ Cancer-specific survival } & & Overall survival \\
\cline { 2 - 3 } \cline { 5 - 6 } 1-year survival rate & Sub-lobectomy vs. lobectomy & P value & Sub-lobectomy vs. lobectomy & P value \\
2-year survival rate & $59.0 \%$ vs. $72.7 \%$ & $<0.001$ & $56.7 \%$ vs. $70.3 \%$ & $<0.001$ \\
3-year survival rate & $43.2 \%$ vs. $54.9 \%$ & $<0.001$ & $40.9 \%$ vs. $51.5 \%$ & $29.1 \%$ vs. $41.0 \%$ \\
\hline
\end{tabular}

patients into two groups according to lymph node dissection number ( $<9$ or $\geq 9$ ) (Figure 4). The results showed $\geq 9$ lymph node dissections only improved survival in the sub-lobar resection population (CSS HR: 0.66, 95\% CI: 0.50-0.87, $\mathrm{P}=0.011$ ), not the lobectomy patients (CSS HR: $0.97,95 \%$ CI: $0.70-1.35, \mathrm{P}=0.89)$.

\section{Subgroup analysis}

We further investigated whether lobectomy was associated with better survival outcomes in different population subtypes. The CSS and OS outcomes displayed similar results (Figure 5). With the exception of stage T4 and brain metastatic patients, all of the NSCLC patient subtypes 


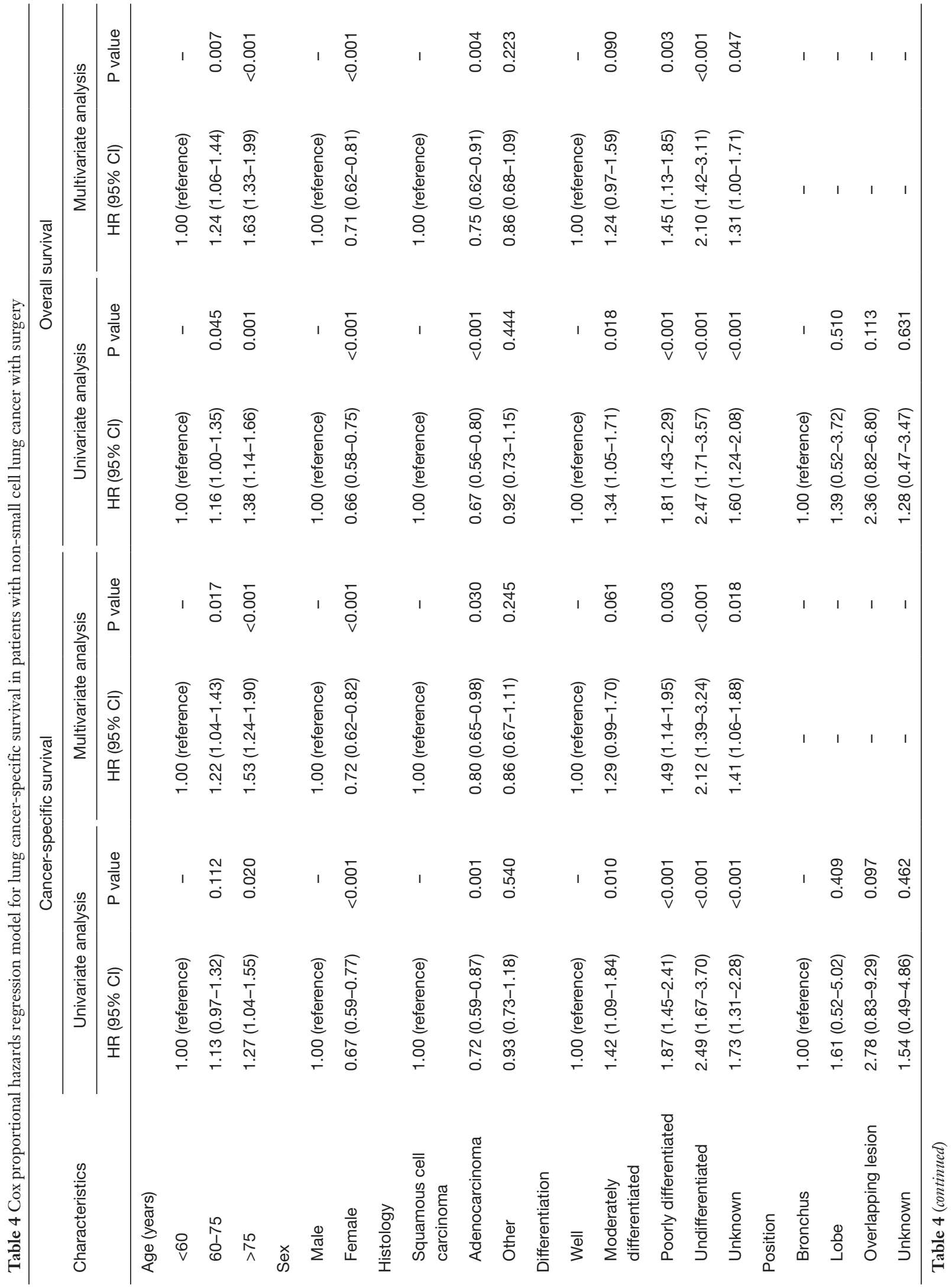




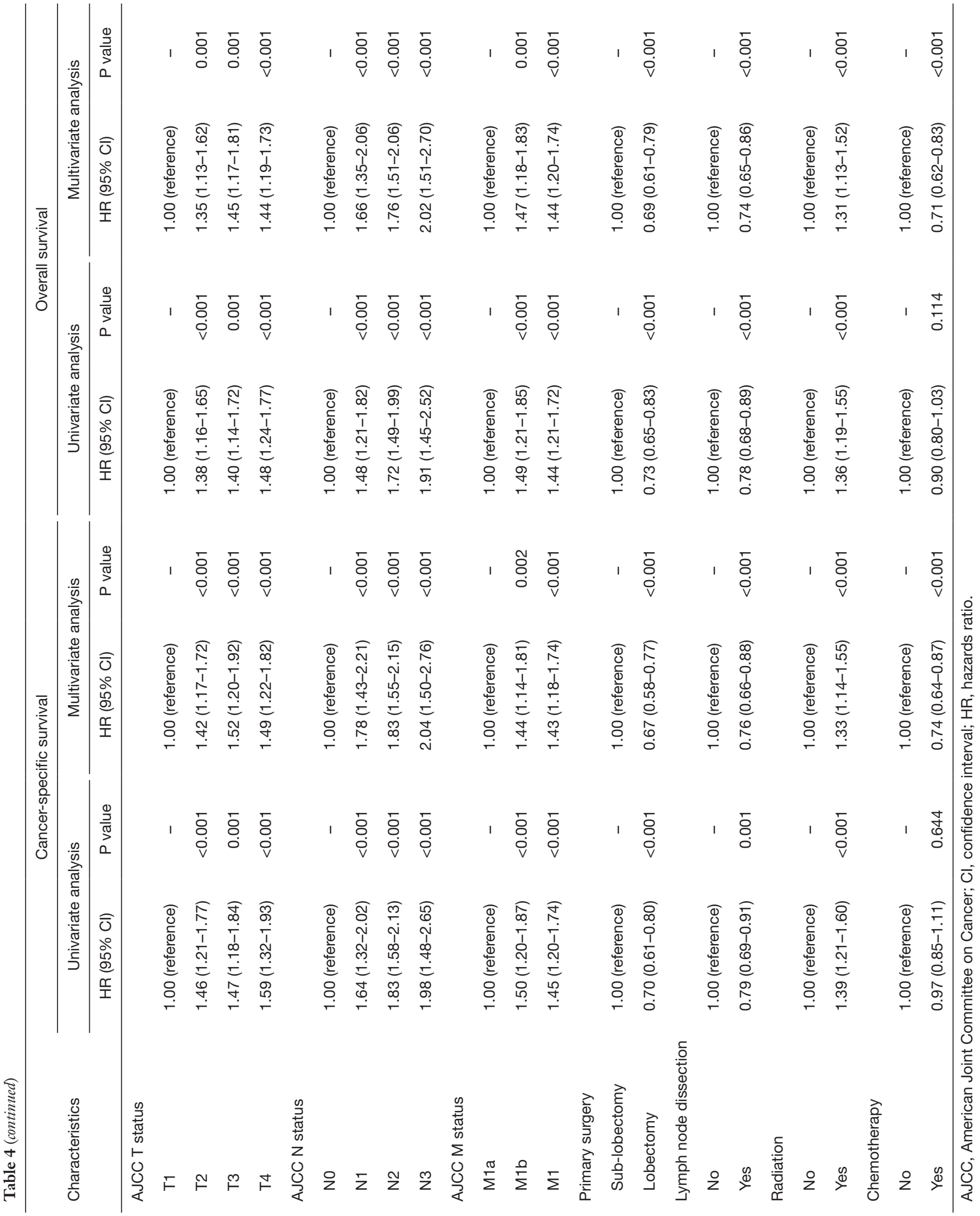


Table 5 Survival rate of stage IV non-small cell lung cancer patients in the sub-lobar resection cohort

\begin{tabular}{|c|c|c|c|c|}
\hline Survival rate & \multicolumn{2}{|l|}{ Cancer-specific survival } & \multicolumn{2}{|l|}{ Overall survival } \\
\hline 1-year survival rate & $54.7 \%$ vs. $61.7 \%$ & 0.103 & $51.6 \%$ vs. $61.0 \%$ & 0.103 \\
\hline 2-year survival rate & $42.7 \%$ vs. $41.7 \%$ & 0.779 & $40.3 \%$ vs. $40.4 \%$ & 0.792 \\
\hline 3-year survival rate & $32.1 \%$ vs. $32.2 \%$ & 0.876 & $29.3 \%$ vs. $30.1 \%$ & 0.876 \\
\hline
\end{tabular}

A

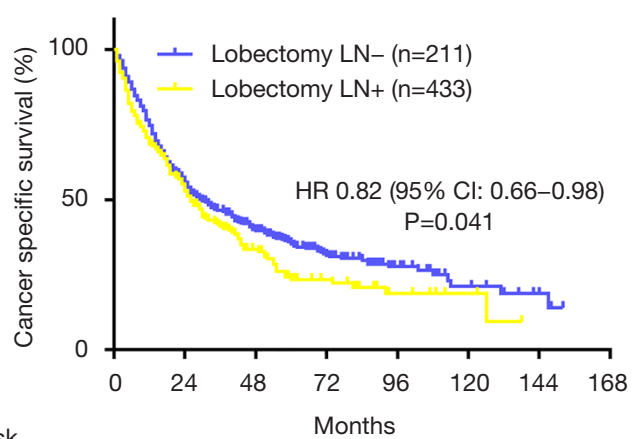

No. at Risk

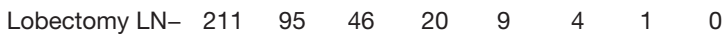

Lobectomy LN+ $\begin{array}{llllllll}433 & 207 & 118 & 65 & 29 & 12 & 5 & 0\end{array}$

\section{C}

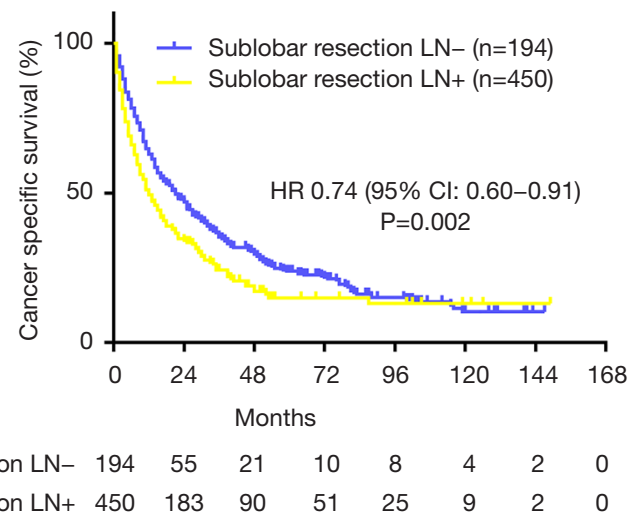

B

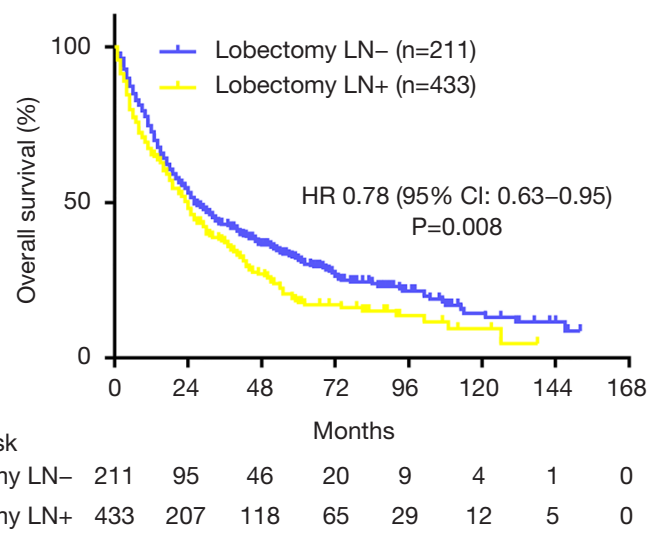

No. at Risk

\begin{tabular}{|c|c|c|c|c|c|c|c|}
\hline Lobectomy LN- & 211 & 95 & 46 & 20 & 9 & 4 & 1 \\
\hline Lobectomy LN+ & 433 & 207 & 118 & 65 & 29 & 12 & \\
\hline
\end{tabular}

D

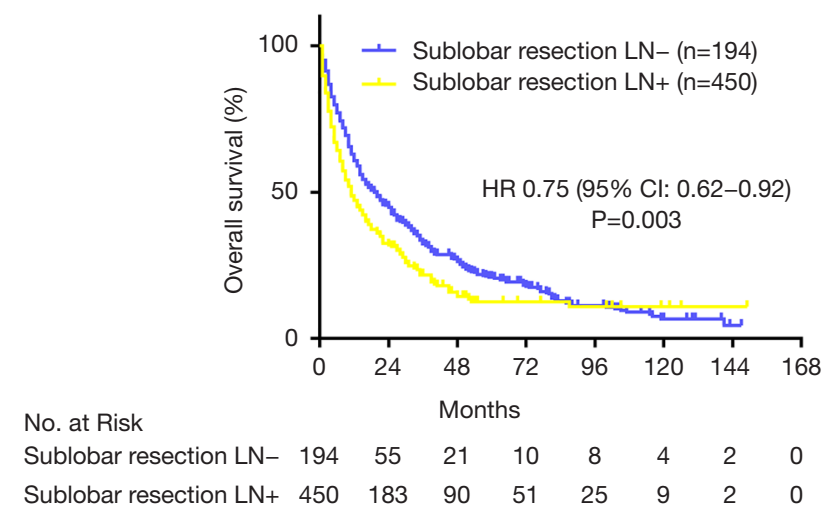

Figure 3 Impact of lymph node (LN) dissection on survival outcomes. (A) Cancer-specific survival following lobectomy; (B) overall survival following lobectomy; (C) cancer-specific survival following sub-lobar resection; (D) overall survival following sub-lobar resection. HR, hazard ratio; CI, confidence interval.

benefitted more from lobectomy than sub-lobar resection.

\section{Discussion}

There is growing evidence in recent years that supports the value of primary tumor resection for advanced-stage
NSCLC patients. However, to the best of our knowledge, there has been no study with the primary aim to compare the survival outcomes in relation to the specific surgical strategies employed. There is little evidence as to which is the better strategy for metastatic NSCLC patients. This was a population-based PSM study that was conducted to 
A

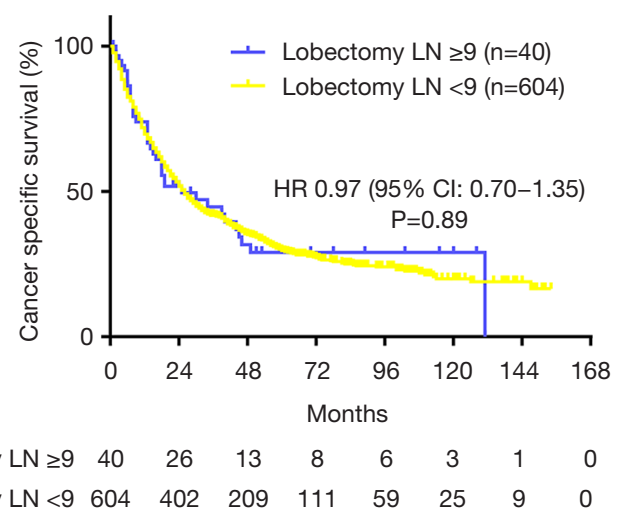

C

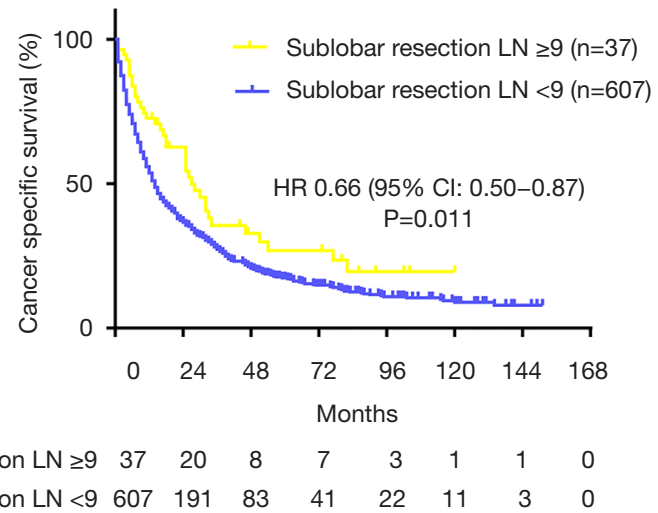

B

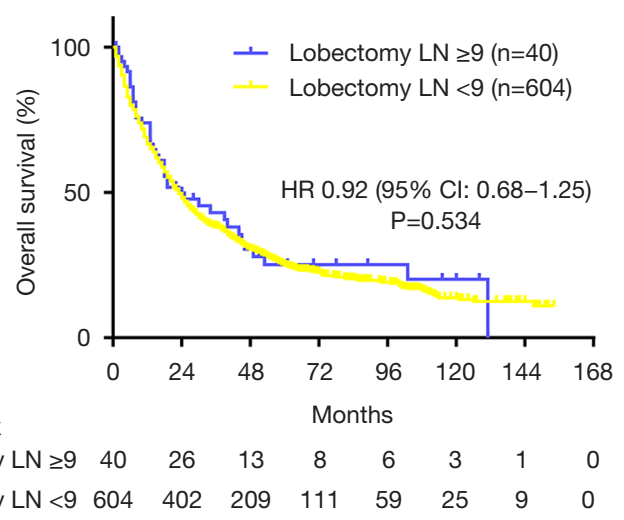

D

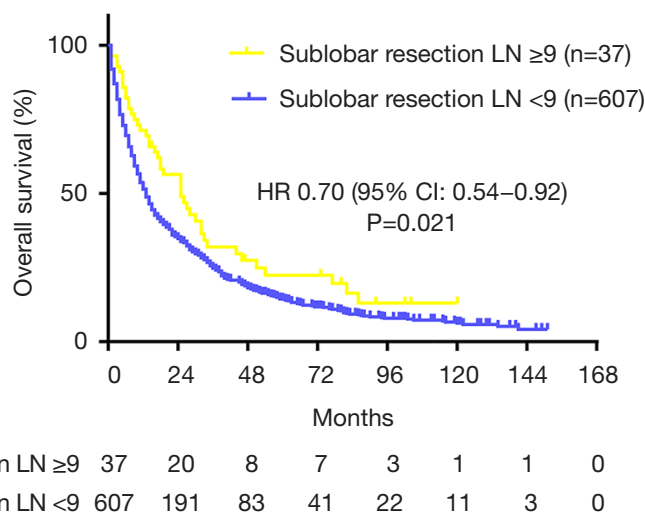

Figure 4 Impact of lymph node dissection number on survival outcomes. (A) Cancer-specific survival following lobectomy; (B) overall survival following lobectomy; (C) cancer-specific survival following sub-lobar resection; (D) overall survival following sub-lobar resection. HR, hazard ratio; CI, confidence interval.

assess the respective relative value of lobectomy and sublobar resection in stage IV NSCLC patients. The results indicated that lobectomy independently significantly improved both CSS and OS compared with sub-lobar resection. Subgroup analysis revealed that, compared with sub-lobar resection, all of the subgroup patients, with the exception of the stage T4 patients, benefitted from lobectomy. Systemic therapy is essential for advanced disease. Radical standard chemotherapy or target therapy or immunotherapy are still needed for these patients. Surgery (lobectomy) may bring more benefit.

According to the National Comprehensive Cancer Network (NCCN) guidelines, patients who have single brain or adrenal metastasis, but the primary tumor is T1-2, N0-1, or T3, local treatment of the metastatic NSCLC lesion followed by resection of the primary tumor is recommended (13) The guidelines also recommend the resection of contralateral lung nodules. However, published studies on local management strategies for stage IV NSCLC are generally single-institution retrospective studies. As such, surgeons have extremely limited evidence to provide patients as an estimate of the prognosis associated with aggressive treatment. Yang et al. investigated the treatment effect of surgery for metastatic NSCLC with the use of National Cancer Database (14), and found that surgery for cT1-2, N0-1, M1, cT3, N0, or M1 disease is associated with a 5 -year survival of $25 \%$. The supporting guidelines recommend surgery for select patients with stage IV disease. In the subgroup analysis, compared with lobectomy, pneumonectomy (HR: $1.58,95 \%$ CI: 1.31-1.90, $\mathrm{P}<0.001$ ), segmentectomy (HR: $1.36,95 \% \mathrm{CI}$ : 1.08-1.71, $\mathrm{P}=0.009$ ), and wedge resection (HR: 1.70, 95\% CI: $1.55-1.88, \mathrm{P}<0.001)$ were all found to be associated with worse survival outcomes in stage IV NSCLC patients. 


\begin{tabular}{|c|c|c|c|c|}
\hline Subgroup & $\begin{array}{l}\text { Sublobar resection } \\
\text { no. of erents }(\%)\end{array}$ & $\begin{array}{l}\begin{array}{l}\text { Lobectomy } \\
\text { no. of events }(\%)\end{array} \\
\end{array}$ & d Ratio ( $95 \%$ CI) & PValue \\
\hline Overall & $644(50.0)$ & $644(50.0)$ & $0.67(0.58-0.77)$ & $<0.001$ \\
\hline Age & & & & \\
\hline$<60$ & $201(31.2)$ & $184(28.6)$ & $0.64(0.49-0.84)$ & 0.001 \\
\hline $60-75$ & $326(50.6)$ & $342(53.1)$ & $0.79(0.65-0.96)$ & 0.017 \\
\hline$>75$ & $117(18.2)$ & $118(18.3)$ & $0.50(0.35-0.70)$ & $<0.001$ \\
\hline Gender & & & & \\
\hline Male & $322(50.0)$ & $309(48.0)$ & $0.68(0.56-0.82)$ & $<0.001$ \\
\hline Female & $322(50.0)$ & $335(52.0)$ & $0.66(0.54-0.81)$ & $<0.001$ \\
\hline Histology & & & & \\
\hline Squamous carcinoma & $83(12.9)$ & $89(13.8)$ & $0.45(0.29-0.69)$ & $<0.001$ \\
\hline Adenocarcinoma & $468(72.7)$ & $445(69.1)$ & $0.74(0.63-0.88)$ & $<0.001$ \\
\hline Others & $93(14.4)$ & $110(17.1)$ & $0.56(0.39-0.80)$ & 0.001 \\
\hline AJCC T status & & & & \\
\hline $\mathrm{T} 1$ & $138(21.4)$ & $158(24.5)$ & $0.59(0.43-0.81)$ & 0.001 \\
\hline $\mathrm{T} 2$ & 195 (30.3) & $195(30.3)$ & $0.52(0.40-0.68)$ & $<0.001$ \\
\hline $\mathrm{T} 3$ & $107(16.6)$ & $107(16.6)$ & $0.61(0.42-0.88)$ & 0.008 \\
\hline $\mathrm{T} 4$ & $204(31.7)$ & $184(28.6)$ & $0.86(0.67-1.11)$ & 0.239 \\
\hline AJCC N status & & & & \\
\hline No & $340(52.8)$ & $364(56.5)$ & $0.72(0.59-0.88)$ & 0.001 \\
\hline N1 & $64(9.9)$ & $77(12.0)$ & $0.60(0.38-0.96)$ & 0.032 \\
\hline $\mathrm{N} 2$ & $205(31.8)$ & $170(26.4)$ & $0.66(0.52-0.85)$ & 0.001 \\
\hline $\mathrm{N} 3$ & $35(5.4)$ & $33(5.1)$ & $0.38(0.17-0.84)$ & 0.017 \\
\hline AJCC M status & & & & \\
\hline M1a & $141(21.9)$ & $149(23.1)$ & $0.51(0.35-0.74)$ & $<0.001$ \\
\hline Mlb & $148(23.0)$ & $148(23.0)$ & $0.53(0.38-0.75)$ & $<0.001$ \\
\hline M & $355(55.1)$ & $347(53.9)$ & $0.75(0.63-0.90)$ & 0.002 \\
\hline Location of metastasis (a fter & & & & \\
\hline Bone & $41(14.6)$ & $56(16.4)$ & $0.64(0.49-0.79)$ & $<0.001$ \\
\hline Brin & $73(26.0)$ & $69(20.2)$ & $0.77(0.62-0.97)$ & 0.051 \\
\hline Liver & $34(12.1)$ & $48(14.0)$ & $0.69(0.55-0.83)$ & 0.004 \\
\hline PleuralPeriardial effusion & $110(39.1)$ & $131(38.3)$ & $\begin{array}{l}0.09(0.55-0.03) \\
0.44(0.29-0.59)\end{array}$ & $<0.001$ \\
\hline Contralateral lung nodules & $23(8.2)$ & $38(11.1)$ & $0.51(0.39-0.65)$ & $<0.001$ \\
\hline Meta sta sis number (after 2 & & & & \\
\hline Only one & $199(70.8)$ & $239(70.0)$ & $0.45(0.30-0.61)$ & $<0.001$ \\
\hline More than one & $51(18.2)$ & $67(19.6)$ & $0.65(0.55-0.76)$ & $<0.001$ \\
\hline More than three & $31(11.0)$ & $36(10.4)$ & $0.78(0.65-0.90)$ & 0.032 \\
\hline $\begin{array}{l}\text { Madiation minee } \\
\text { Rate }\end{array}$ & & & & \\
\hline No/Unknown & $423(65.7)$ & $422(65.5)$ & $0.62(0.49-0.81)$ & 0.021 \\
\hline Yes & $221(34.3)$ & $222(34.5)$ & $0.77(0.60-0.87)$ & 0.019 \\
\hline Chemotherapy & & & & \\
\hline No/Unknown & $270(41.9)$ & $290(45.0)$ & $0.65(0.55-0.82)$ & 0.03 \\
\hline Yes & $374(58.1)$ & $354(55.0)$ & $0.70(0.57-0.81)$ & 0.031 \\
\hline Surgery to metastasis site & & & & \\
\hline No/Unknown & $313(48.6)$ & $359(55.7)$ & $0.71(0.58-0.87)$ & 0.005 \\
\hline Yes & $331(51.4)$ & $285(44.3)$ & $0.64(0.54-0.81)$ & 0.03 \\
\hline & & 0.5 & 1.5 & \\
\hline Subgroup & $\begin{array}{l}\text { Sublobar resection } \\
\text { no. of events }(\%)\end{array}$ & $\begin{array}{l}\text { L obectomy } \\
\text { no. of events (\%) }\end{array}$ & ird Ratio $95 \%$ CI) & PValue \\
\hline & & & & \\
\hline Overall & $644(50.0)$ & $644(50.0)$ & $0.69(0.61-0.79)$ & $<0.001$ \\
\hline Age & & & & \\
\hline$<60$ & $201(31.2)$ & $184(28.6)$ & $0.67(0.52-0.87)$ & 0.002 \\
\hline $60-75$ & $326(50.6)$ & $342(53.1)$ & $0.77(0.64-0.93)$ & 0.006 \\
\hline$>75$ & $117(18.2)$ & $118(18.3)$ & $0.57(0.42-0.78)$ & 0.001 \\
\hline Gender & & & & \\
\hline Male & $322(50.0)$ & $309(48.0)$ & $0.70(0.59-0.84)$ & $<0.001$ \\
\hline Female & $322(50.0)$ & $\begin{array}{l}309(40.0) \\
335(52.0)\end{array}$ & $0.68(0.56-0.82)$ & $<0.001$ \\
\hline Histology & & & & \\
\hline Squamous carcinoma & $83(12.9)$ & $89(13.8)$ & $0.45(0.30-0.67)$ & $<0.001$ \\
\hline Adenocarinoma & $468(72.7)$ & $445(69.1)$ & $0.75(0.64-0.88)$ & $<0.001$ \\
\hline Others & $93(14.4)$ & $110(17.1)$ & $0.63(0.45-0.88)$ & 0.006 \\
\hline AJCC T status & & & & \\
\hline T1 & $138(21.4)$ & $158(24.5)$ & $0.58(0.43-0.77)$ & $<0.001$ \\
\hline $\mathrm{T} 2$ & $195(30.3)$ & $195(30.3)$ & $0.57(0.44-0.73)$ & $<0.001$ \\
\hline T3 & 107 (16.6) & $107(16.6)$ & $0.66(0.47-0.93)$ & 0.017 \\
\hline $\mathrm{T} 4$ & $204(31.7)$ & $184(28.6)$ & $0.88(0.69-1.12)$ & 0.307 \\
\hline AJCC N status & & & & \\
\hline No & $340(52.8)$ & $364(56.5)$ & $0.73(0.61-0.88)$ & 0.001 \\
\hline N1 & $64(9.9)$ & 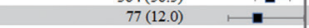 & $0.63(0.40-0.99)$ & 0.043 \\
\hline $\mathrm{N} 2$ & $205(31.8)$ & 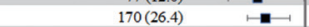 & $0.69(0.55-0.88)$ & 0.003 \\
\hline N3 & $35(5.4)$ & $33(5.1)$ & $0.41(0.19-0.86)$ & 0.018 \\
\hline AJCC M status & & & & \\
\hline M1a & $141(21.9)$ & $149(23.1)$ & $0.58(0.41-0.82)$ & 0.002 \\
\hline M1b & $148(23.0)$ & $148(23.0)$ & $0.57(0.42-0.79)$ & 0.001 \\
\hline $\mathrm{M}$ & $355(55.1)$ & $347(53.9)$ & $0.75(0.64-0.89)$ & 0.001 \\
\hline Location of metastasis (afte & & & & \\
\hline Bone & $41(14.6)$ & $56(16.4)$ & $0.65(0.51-0.79)$ & $<0.001$ \\
\hline Brain & $73(26.0)$ & $69(20.2)$ & $0.81(0.65-1.01)$ & 0.028 \\
\hline Liver & $34(12.1)$ & $48(14.0)$ & $0.70(0.55-0.82)$ & 0.003 \\
\hline Pleura/Periardial effusion & $110(39.1)$ & $131(38.3)$ & $0.45(0.30-0.61)$ & $<0.001$ \\
\hline Contralateral lung nodules & $23(8.2)$ & 38 (11.1) & $0.51(0.38-0.65)$ & $<0.001$ \\
\hline Metastasis number (after 2 & & & & \\
\hline Only one & $199(70.8)$ & $239(70.0)$ & $0.49(0.33-0.67)$ & $<0.001$ \\
\hline More than one & $51(18.2)$ & $67(19.6)$ & $0.64(0.56-0.74)$ & 0.002 \\
\hline More than three & $31(11.0)$ & $36(10.4)$ & $0.79(0.65-0.91)$ & 0.034 \\
\hline $\begin{array}{l}\text { Radiation } \\
\text { Ren }\end{array}$ & & & & \\
\hline No/Unknown & $423(65.7)$ & $422(65.5)$ & $0.62(0.48-0.81)$ & 0.017 \\
\hline Yes & $221(34.3)$ & $222(34.5)$ & $0.77(0.61-0.86)$ & 0.022 \\
\hline Chemotherapy & & & & \\
\hline No/Unknown & $270(41.9)$ & $290(45.0)$ & $0.68(0.55-0.85)$ & 0.02 \\
\hline Yes & $374(58.1)$ & $354(55.0)$ & $0.71(0.57-0.82)$ & 0.028 \\
\hline Surgery to metastasis site & & & & \\
\hline No/Unknown & $313(48.6)$ & $359(55.7)$ & $0.69(0.56-0.87)$ & 0.008 \\
\hline Yes & $331(51.4)$ & $285(44.3)$ & $0.66(0.55-0.80)$ & 0.01 \\
\hline
\end{tabular}

Figure 5 Subgroup analysis (for) stage IV non-small cell lung cancer patients according to surgery type. (A) Cancer-specific survival; (B) overall survival. 
The subgroup analysis did not match the patients' baseline characteristics; therefore, potential patient selection bias may have been present. The ideal surgery type for stage IV NSCLC patients is thus still undetermined. Based on the SEER database, and using PSM analysis, we found that lobectomy should be considered as the preferred surgery for stage IV NSCLC, with the exception of stage T4 patients. Lymph node dissection may provide additional survival.

The role of surgery in advanced-stage NSCLC is always important for diagnostic and palliative purposes $(15,16)$. As individualized medicinal protocols have taken a more prominent role in the care of advanced NSCLC patients and treatment decisions are now based on histological molecular subtypes, surgeons are performing more operations to obtain adequate tissue for detailed subtyping of NSCLC. Sub-lobar resection is suitable for biopsy performed for diagnostic and palliative purposes; however, lobectomy and lymph node dissection provide a more aggressive and comprehensive reduction of the primary tumor, which suggests the potential for a better survival outcome. Mitchell et al. found that the T stage is also the significant prognostic factor in stage IV NSCLC patients, and comprehensive local consolidative therapy results in a longer OS (HR: 0.67, 95\% CI: 0.46-0.97, P=0.034) (6). Their findings also support a more aggressive and thorough local treatment strategy for metastatic NSCLC.

Oligometastatic NSCLC is one of the indications strongly indicated to receive local consolidative therapy (17). Ashworth et al. reported that the survival outcomes in patients with oligometastatic NSCLC are highly variable, and half of patients progress within approximately 12 months; however, long-term survivors do exist (18). The definitive treatment for the primary lung tumor and low-burden thoracic tumors are strongly associated with improved long-term survival. Many studies have focused on local treatments for oligometastatic NSCLC, with the use of surgery and radiation, both for primary tumor and metastatic sites. Numerous single-institution studies have demonstrated that the surgical management of patients with oligometastatic NSCLC to the brain, adrenal gland, and contralateral lung is associated with superior long-term survival (19-21). Although surgery is not recommended in the NCCN guidelines for the management of metastatic NSCLC with pleural dissemination (13), several published studies have reported on a survival benefit in this population (22). In this population-based analysis, we found that the patients in all of the subgroups, with the exception of stage T4, achieved significant survival benefit from lobectomy compared with sub-lobar resection. However, clinical information on oligometastatic NSCLC and patients with pleural dissemination was not available in the SEER database, and we were unable to verify the treatment effect of lobectomy on this population. Further real-world studies are warranted. We

Several potential mechanisms may explain the survival benefit of the aggressive surgical strategy. First, it is possible that the larger and comprehensive extended resection reduced the number of de novo resistant malignant cells that cannot be killed or inhibited by initial and maintenance systemic therapy, prolonging life expectancy $(23,24)$. Second, thorough primary tumor resection would potentiate the effects of perioperative systemic therapy; for example, in a mouse model, after neoadjuvant immunotherapy, mice that underwent primary tumor resection had the benefit of an extension of long-term survival, while mice that did not receive local treatment had reduced survival (25). Third, the continued existence of primary tumors after systemic therapy would promote the growth of distant micrometastases, therefore reducing the primary tumor burden by the maximum extent possible is important so the growth of distant micrometastatic disease will also be decreased. Notably, these mechanisms are not mutually exclusive, and more than one may contribute to the benefits of lobectomy for advanced NSCLC.

We recently created a practical predictive model that might be used to identify the optimal candidates for surgical resection of the primary tumor among stage IV NSCLC patients (26). We demonstrated that only certain stage IV NSCLC patients would benefit from surgery and the potential benefit would vary based on primary tumor characteristics.

Although this population-based analysis suggests a longterm survival benefit and clinical efficacy of lobectomy and lymph node dissection for patients with stage IV NSCLC, the data should be interpreted with caution for the following reasons: (I) information on preoperative comorbidities for patients was lacking, which might lead to selection bias (for) of the treatment choice; (II) detailed information and the distribution of patients' metastatic disease were not available, so we were unable to explore whether oligometastatic disease would affect the benefits of lobectomy; and (III) data on systemic therapies were not available. This lack of information regarding target therapies and immunotherapy is a limitation of the current study. Although the number of stage IV patients who underwent primary tumor resection is limited in each medical center, 
the analysis of the curative effect of lobectomy in these patients is challenging. The SEER database is the only comprehensive population-based database with open access worldwide, providing the most ideal approach to study the survival of these patients. Prospective randomized trials are needed to further validate the benefits of surgery types in metastatic NSCLC patients.

\section{Conclusions}

The findings of the present study demonstrated that lobectomy for primary tumors may further improve the survival of stage IV NSCLC patients compared with sublobar resection when radical treatment of primary site was indicated. Future clinical trials should focus on optimal metastatic NSCLC candidates for this type of surgery.

\section{Acknowledgments}

The authors appreciate the academic support from the AME Lung Cancer Collaborative Group.

Funding: None.

\section{Footnote}

Reporting Checklist: The authors have completed the STROBE reporting checklist. Available at http://dx.doi. org/10.21037/tlcr-21-39

Conflicts of Interest: All authors have completed the ICMJE uniform disclosure form (available at http://dx.doi. org/10.21037/tlcr-21-39). WL serves as an unpaid Editorial Board Member of Translational Lung Cancer Research from Apr 2018 to Apr 2021. HL serves as an unpaid current section editor for this journal. The other authors have no conflicts of interest to declare.

Ethical Statement: The authors are accountable for all aspects of the work in ensuring that questions related to the accuracy or integrity of any part of the work are appropriately investigated and resolved. The study was conducted in accordance with the Declaration of Helsinki (as revised in 2013).

Open Access Statement: This is an Open Access article distributed in accordance with the Creative Commons Attribution-NonCommercial-NoDerivs 4.0 International License (CC BY-NC-ND 4.0), which permits the non- commercial replication and distribution of the article with the strict proviso that no changes or edits are made and the original work is properly cited (including links to both the formal publication through the relevant DOI and the license). See: https://creativecommons.org/licenses/by-nc-nd/4.0/.

\section{References}

1. Siegel RL, Miller KD, Jemal A. Cancer statistics, 2018. CA Cancer J Clin 2018;68:7-30.

2. Jemal A, Center MM, DeSantis C, et al. Global patterns of cancer incidence and mortality rates and trends. Cancer Epidemiol Biomarkers Prev 2010;19:1893-907.

3. Morgensztern D, Ng SH, Gao F, et al. Trends in stage distribution for patients with non-small cell lung cancer: a National Cancer Database survey. J Thorac Oncol 2010;5:29-33.

4. Lin J, McGlynn KA, Nations JA, et al. Comorbidity and stage at diagnosis among lung cancer patients in the US military health system. Cancer Causes Control 2020;31:255-61.

5. Cancer Fact and Figures 2017. Atlanta: American Cancer Society. American Cancer Society; 2017 [cited 2017]; Available online: http://www.cancer.org/acs/ groups/content/@research/documents/webcontent/ acspc-042151.pdf

6. Mitchell KG, Farooqi A, Ludmir EB, et al. Improved Overall Survival With Comprehensive Local Consolidative Therapy in Synchronous Oligometastatic Non-Small-Cell Lung Cancer. Clin Lung Cancer 2020;21:37-46.e7.

7. Arrieta O, Barron F, Maldonado F, et al. Radical consolidative treatment provides a clinical benefit and long-term survival in patients with synchronous oligometastatic non-small cell lung cancer: A phase II study. Lung Cancer 2019;130:67-75.

8. Gomez DR, Tang C, Zhang J, et al. Local Consolidative Therapy Vs. Maintenance Therapy or Observation for Patients with Oligometastatic Non-Small-Cell Lung Cancer: Long-Term Results of a Multi-Institutional, Phase II, Randomized Study. J Clin Oncol 2019;37:1558-65.

9. Abdel-Rahman O. Outcomes of Surgery as Part of the Management of Metastatic Non-Small-Cell Lung Cancer: A Surveillance, Epidemiology and End Results Database Analysis. Cancer Invest 2018;36:238-45.

10. David EA, Clark JM, Cooke DT, et al. The Role of Thoracic Surgery in the Therapeutic Management of Metastatic Non-Small Cell Lung Cancer. J Thorac Oncol 2017;12:1636-45. 
11. Sun Z, Sui X, Yang F, et al. Effects of primary tumor resection on the survival of patients with stage IV extrathoracic metastatic non-small cell lung cancer: A population-based study. Lung Cancer 2019;129:98-106.

12. Doll KM, Rademaker A, Sosa JA. Practical Guide to Surgical Data Sets: Surveillance, Epidemiology, and End Results (SEER) Database. JAMA Surg 2018;153:588-9.

13. Ettinger DS, Aisner DL, Wood DE, et al. NCCN Guidelines Insights: Non-Small Cell Lung Cancer, Version 5.2018. J Natl Compr Canc Netw 2018;16:807-21.

14. Yang CJ, Gu L, Shah SA, et al. Long-term outcomes of surgical resection for stage IV non-small-cell lung cancer: A national analysis. Lung Cancer 2018;115:75-83.

15. Cooke DT, Gandara DR, Goodwin NC, et al. Outcomes and efficacy of thoracic surgery biopsy for tumor molecular profiling in patients with advanced lung cancer. J Thorac Cardiovasc Surg 2014;148:36-40.

16. Bell D, Wright G. A retrospective review of the palliative surgical management of malignant pleural effusions. BMJ Support Palliat Care 2014;4:161-6.

17. Ashworth AB, Senan S, Palma DA, et al. An individual patient data metaanalysis of outcomes and prognostic factors after treatment of oligometastatic non-small-cell lung cancer. Clin Lung Cancer 2014;15:346-55.

18. Ashworth A, Rodrigues G, Boldt G, et al. Is there an oligometastatic state in non-small cell lung cancer? A systematic review of the literature. Lung Cancer 2013;82:197-203.

19. Gray PJ, Mak RH, Yeap BY, et al. Aggressive therapy for patients with non-small cell lung carcinoma and synchronous brain-only oligometastatic disease is

Cite this article as: Hao Z, Liang $\mathrm{H}$, Zhang $\mathrm{Y}$, Wei W, Lan Y, Qiu S, Lin G, Wang R, Liu Y, Chen Y, Huang J, Wang W, Cui F, Goto T, Jeong JY, Veronesi G, Lopez-Pastorini A, Igai H, Liang W, He J, Liu J. Surgery for advanced-stage non-small cell lung cancer: lobectomy or sub-lobar resection? Transl Lung Cancer Res 2021;10(3):1408-1423. doi: 10.21037/tlcr-21-39 associated with long-term survival. Lung Cancer 2014;85:239-44.

20. Mercier O, Fadel E, de Perrot M, et al. Surgical treatment of solitary adrenal metastasis from non-small cell lung cancer. J Thorac Cardiovasc Surg 2005;130:136-40.

21. Congedo MT, Cesario A, Lococo F, et al. Surgery for oligometastatic non-small cell lung cancer: longterm results from a single center experience. J Thorac Cardiovasc Surg 2012;144:444-52.

22. Okamoto T, Iwata T, Mizobuchi T, et al. Pulmonary resection for lung cancer with malignant pleural disease first detected at thoracotomy. Eur J Cardiothorac Surg 2012;41:25-30.

23. Jabbour SK, Kim S, Haider SA, et al. Reduction in Tumor Volume by Cone Beam Computed Tomography Predicts Overall Survival in Non-Small Cell Lung Cancer Treated with Chemoradiation Therapy. Int J Radiat Oncol Biol Phys 2015;92:627-33.

24. Kanzaki H, Kataoka M, Nishikawa A, et al. Impact of early tumor reduction on outcome differs by histological subtype in stage III non-small-cell lung cancer treated with definitive radiotherapy. Int J Clin Oncol 2016;21:853-61.

25. Liu J, Blake SJ, Yong MC, et al. Improved Efficacy of Neoadjuvant Compared to Adjuvant Immunotherapy to Eradicate Metastatic Disease. Cancer Discov 2016;6:1382-99.

26. Liang H, Liu Z, Huang J, et al. Identifying optimal candidates for primary tumor resection among metastatic non-small cell lung cancer patients: a population-based predictive model. Transl Lung Cancer Res 2021;10:279-91. 